\title{
IDENTIFIKASI KAWASAN NILAI KONSERVASI TINGGI 4 (NKT 4) DI DAERAH ALIRAN SUNGAI WAFOR, KABUPATEN SUPIORI, PROVINSI PAPUA
}

\author{
Khristian Enggar Pamuji \\ Prodi Fisika Jurusan Fisika FMIPA UNIPA \\ Jl. Gunung salju Amban, Manokwari - Kode Pos: 98314 \\ e-mail : k_enggar_p@yahoo.com
}

\begin{abstract}
ABSTRAK
Salah satu atribut dalan NKT adalah Kawasan yang memberikan jasa ekosistem dasar pada situasi yang kritis atau sangat penting. Suatu wilayah dapat dipertimbangkan sebagai NKT 4 jika berperan dalam melindungi atau menyediakan jasa ekosistem mendasar dalam situasi penting, termasuk perlindungan daerah tangkapan air dan kontrol erosi pada tanah rentan dan lereng. Saat ini telah dilakukan penilaian keberadaan NKT 4 Daerah Aliran Sungai (DAS) Wafor yang berada di Distrik Supiori Timur, Kabupaten Supiori, Provinsi Papua. Sungai-sungai di DAS Wafor dimanfaatkan oleh masyarakat lokal sebagai sumber air bersih. Sungai Wafor memiliki rasio relief rata-rata antara 0.04, namum dibeberapa tempat terutama bagian hulu, kemiringan lereng mencapai $30 \%-40 \%$. Faktor bentuk (Form factor/ Rf) DAS Wafor memiliki nilai 0.62 atau bentuk DAS relatif membulat dan rasio elongasi sebesar 0.71 . Daerah aliran sungai yang membulat, debit puncak datangnya lama, begitu juga penurunannya, sehingga dapat efektif dalam mengendalikan banjir.DAS Wafor memiliki kerapatan drainase (Dd) $1,03 \mathrm{~km} / \mathrm{km} 2$, artinya setiap $1 \mathrm{~km} 2$ area DAS terpadat panjang total sungai $1,03 \mathrm{~km}$. Kerapatan drainase ini termasuk kategori sedang. Hal ini tentunya akan sangat membantu dalam menghalangi penyebaran titik-titik api jika terjadi kebakaran hutan. Sedimentasi di Sungai Wafor termasuk kategori rendah atau $<50 \mathrm{mg} / \mathrm{L}$. Dengan alur sungai rata-rata tidak lebih dari $20 \mathrm{~km}$, maka dapat disimpulkan bahwa DAS tersebut bekerja efektif dalam mengendalikan erosi.,
\end{abstract}

Kata Kunci : Nilai Konsevasi Tinggi, NKT 4, Jasa Ekosistem, DAS Supiori, Morfometri Sungai,

I. PENDAHULUAN

NKT adalah nilai yang terkandung di dalam kawasan baik itu lingkungan atau sosial yang penting secara lokal maupun global (HCV ToolkitIndonesia, 2008). Salah satu atribut dalan NKT adalah Kawasan yang memberikan jasa ekosistem dasar pada situasi yang kritis atau sangat penting. Jasa ekosistem merupakan keuntungan yang diperoleh manusia melalui ekosistem, termasuk jasa penyediaan seperti makanan dan air; jasa pengaturan seperti pengaturan terhadap banjir, kekeringan, degradasi tanah, dan penyakit; jasa kultural seperti keuntungan rekreasional, spiritual, religi dan keuntungan non-materiil lainnya; serta jasa pendukung lainnya seperti pembentukan tanah dan daur nutrien23.

Suatu wilayah dapat dipertimbangkan sebagai NKT 4 jika berperan dalam melindungi atau menyediakan salah satu dari jasa-jasa tersebut dalam situasi yang kritis. Contohnya sebuah hutan dapat menyediakan fungsi sebagai pengatur aliran air dalam sebuah daerah tangkapan air. Jasa ini dapat dianggap penting jika masyarakat bergantung pada air untuk minum atau irigasi, atau jika pengaturan aliran air menjamin keberadaan perkembangbiakan ikan atau lahan perkebunan yang dijadikan ketergantungan hidup masyarakat setempat. 
Sistem air tawar akan bersinggungan dengan semua sistem produksi berbasis daratan. Beberapa pengembangan pertanian dan perkebunan bergantung pada sistem pengairan yang bersumber dari permukaan maupun bawah tanah, namun bahkan dalam situasi tanpa sistem pengairan sekalipun terdapat kemungkinan munculnya dampak terhadap sistem air tawar melalui perubahan terhadap kualitas dan jumlah air, serta atribut habitat lainnya.

Kabupaten Supiori merupakan salah satu kabupaten pemekaran di Papua. Kabupaten tersebut, secara resmi terbentuk berdasarkan UU.No. 35 Tahun 2003, dan merupakan hasil pemekaran dari kabupaten Biak. Seiring dengan laju pertumbuhan penduduk Kabupaten Supiori yang mencapai 4,78 persen pada tahun 2018, pertumbuhan sentra-sentra ekonomi, serta peningkatan aktivitas pembangunan, kebutuhan terhadap informasi jasa ekosistem semakin juga meningkat. Informasi jasa ekosistem digunakan sebagai bahan pertimbangan dalam berbagai kebijakan dan perencanaan pembangunan berkelanjutan. Untuk itu diperlukan identifikasi, pengelolaan dan pemantauan keberadaan NKT 4 di Kabupaten Supiori, Provinsi Papua.
Tujuan penelitian ini adalah untuk mengidentifikasi kawasan atau Ekosistem yang Penting Sebagai Penyedia Air dan Pengendalian Banjir bagi Masyarakat Hilir NKT, mengidentifikasi kawasan yang Penting Bagi Pengendalian Erosi dan Sedimentasi, dan mengidentifikasi kawasan yang Berfungsi Sebagai Sekat Alam untuk Mencegah Meluasnya Kebakaran Hutan atau Lahan.

\section{METODE PENELITIAN}

\subsection{Lokasi Penelitian}

Penelitian ini dilakukan selama 4 bulan, dimulai dari bulan Agustus 2018 sampai dengan Desember 2018. Daerah penelitian berada di Daerah Aliran Sungai Wafor, yang sebagian besar berada di Distrik Supiori Timur, Kabupaten Supiori (Gambar 1). Penelitian ini dimulai dengan pengumpulan data serta analisis data primer dan data sekunder. Data primer didapat dengan cara melakukan pengukuran dimensi sungai Wafor secara langsung. Beberapa data skunder juga dikumpulkan diantaranya adalah data curah hujan yang dikeluarkan BMKG stasiun meteorologi Frans Kaisepo Biak, serta data DEM dan RBI yang digunakan untuk analisis spasial. 


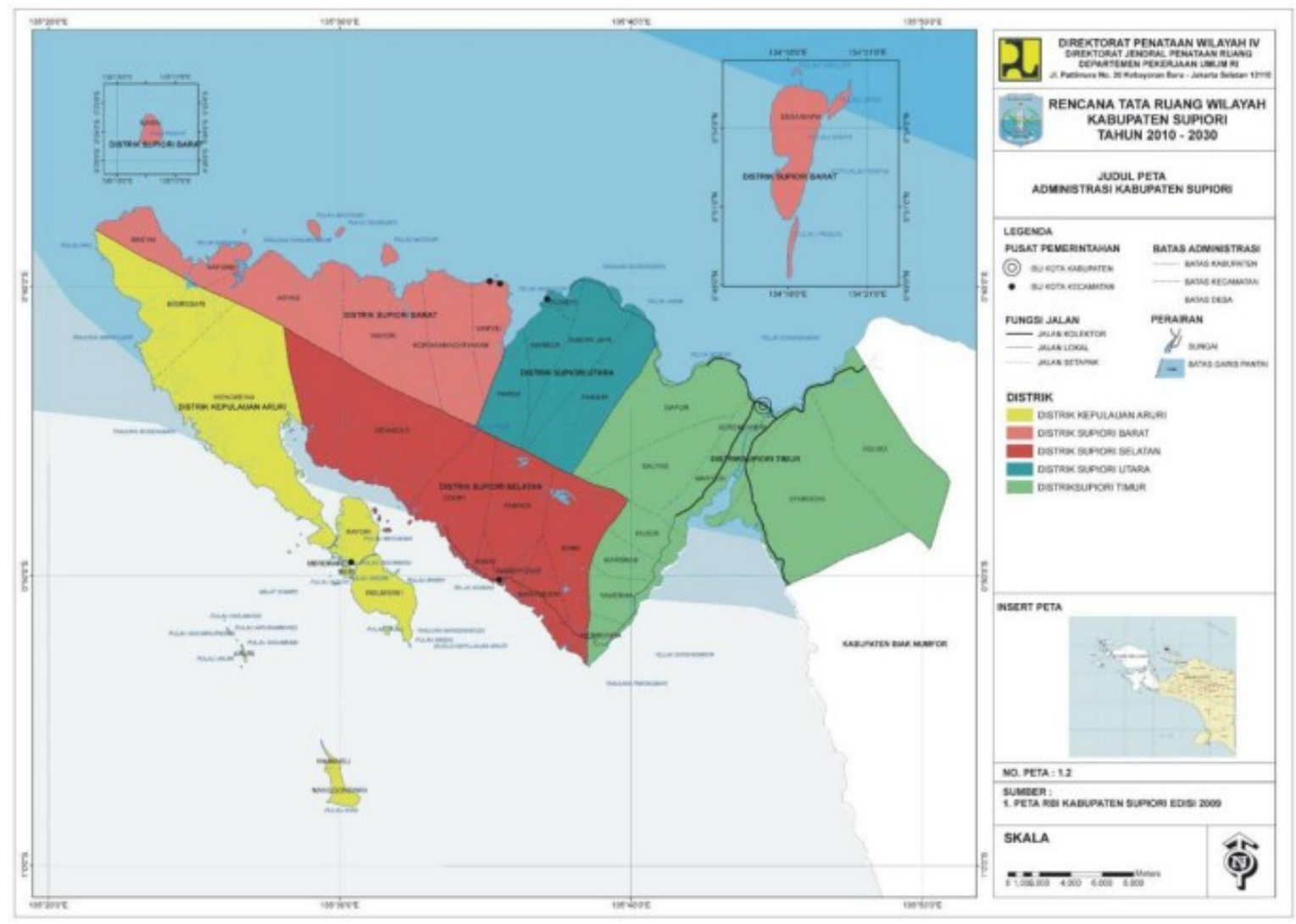

Gambar 1. Peta Kabupaten Supiori

\subsection{Pengolahan Data}

Perhitungan karakteristik morfologi atau morfometrik DAS merupakan prasyarat untuk analisis hidrologi yang lebih rinci terhadap DAS. Data DEM dan SRTM yang digunakan digunkan dalam perhitungan karakteritik sungai menggunakan data spasial. Karakteristik morfometrik DAS yang penting untuk diteliti dapat dilihat pada Tabel 1.

Data primer yang diperoleh dari hasil pengukuran dimensi dan kecepatan arus sungai menggunakan alat current meter, digunakan untuk menentukan debit sungai sesaat. Data curah hujan, dan datadata spasial juga digunakan untuk menentukan ketersediaan air sungai.

Tabel 1. Perhitungan Karakteristik Morfologi DAS

\begin{tabular}{rlc} 
No & \multicolumn{1}{c}{ Parameter } & Persamaan \\
\hline $\mathbf{1}$ & Luas (Ha) & \\
\hline $\mathbf{2}$ & Keliling & $R_{c}=4 \pi A / P^{2}$ \\
\hline $\mathbf{3}$ & Faktor bentuk (Form factor/ Rf) & $R_{e}=2 \sqrt{A_{u} / \pi} / L_{b}$ \\
\hline $\mathbf{4}$ & Rasio elongasi (Elongation ratio/Re) & $R_{h}=H / L_{b}$ \\
\hline $\mathbf{5}$ & Rasio relief $($ Relief ratio/ Rh) & $D d=L / A$ \\
\hline $\mathbf{6}$ & Kerapatan drainage (Drainage density/ Dd $)$ & $F_{s}=N_{u} / A$ \\
\hline $\mathbf{7}$ & Frekuensi sungai (Stream frequency/ Fs) & $R_{t}=N_{u} / P$ \\
\hline $\mathbf{8}$ & Tekstur drainage (Drainage texture/ $R t)$ & $R_{f}=A / L_{b}^{2}$ \\
\hline $\mathbf{9}$ & Faktor bentuk (Form factor/ Rf) \\
\hline
\end{tabular}




\section{HASIL DAN PEMBAHASAN}

\subsection{Keadaan Umum Daerah Penelitian}

Kabupaten Supiori adalah salah satu kabupaten yang berada pada wilayah Provinsi Papua dimana secara geografis terletak antara $134^{\circ} 67^{\prime}-136^{\circ} 48^{\prime}$ Bujur Timur dan $0^{\circ} 55^{\prime}-1^{\circ} 31^{\prime}$ Lintang Selatan. Dengan luas mencapai hingga $634,24 \mathrm{~km}^{2}$ atau 0,2 persen dari keseluruhan wilayah Provinsi Papua menjadikan Kabupaten Supiori sebagai kabupaten terkecil di Provinsi Papua. Secara administratif, Kabupaten Supiori memiliki 5 distrik, dimana Distrik Supiori Timur merupakan distrik yang terluas yaitu mencapai 196,26 $\mathrm{km}^{2}$ atau $30.9 \%$ dari total luas Kabupaten Supiori, sedangkan Distrik Supiori Selatan adalah distrik yang terkecil dengan luas hanya mencapai $87,60 \mathrm{~km}^{2}$ atau hanya 13,81 persen dari total luas wilayah Kabupaten Supiori.

Tahun 2018 jumlah penduduk Kabupaten Supiori sebanyak 20.018 orang dengan luas yang mencapai hingga 634.24 $\mathrm{km}^{2}$, sehingga kepadatan penduduk di Kabupaten Supiori sebesar 32 orang $/ \mathrm{km}^{2}$. Pada tahun 2018 ini laju pertumbuhan penduduk di Kabupaten Supiori mencapai hingga 4,78 persen pertahun. Sebagian besar penduduk Supiori (30.85\%), tinggal di Distrik Supiori Timur (BPS, 2019).

\subsection{Keadaan Iklim}

a) Curah Hujan

Berdasarkan hasil pencatatan untuk tahun 2010-2015 dari Stasiun Meteorologi Frans Kaisepo, Biak, diketahui bahwa curah hujan di wilayah studi tergolong curah hujan tinggi yakni rata-rata 2764.4 mm per Tahun dengan rerata hari hujan 22 hari. Data tersebut jika diperhitungkan dengan kriteria tipe hujan menurut Mohr, maka semua bulan kategorinya dimasukkan dalam bulan basah, dimana bulan basah dengan curah hujan $>100 \mathrm{~mm}$. Berdasarkan klasifikasi Schmidth Ferguson maka akan didapat rata-rata bulan basah $229.82 \mathrm{~mm}$, rata-rata bulan kering $39.2 \mathrm{~mm}$ dan nilai $\mathrm{Q}=17$, sehingga kriteria iklim termasuk kriteria Basah.

b) Periode Curah Hujan

Jika melihat data runtun waktu curah hujan sepanjang tahun 1960 - 2015, rata-rata curah hujan bulanan adalah $287,5 \mathrm{~mm}$, di mana curah hujan tertinggi terjadi pada bulan Agustus yaitu rata-rata $456,1 \mathrm{~mm}$, sedangkan curah hujan terendah terjadi pada bulan November yaitu rata-rata $123,1 \mathrm{~mm}$. Sementara itu, banyaknya hari hujan rata- rata dalam satu bulan di Kabupaten Supiori adalah 22 hari. Grafik curah hujan kabupaten Supiori dari tahun 1960 - 2015 dapat dilihat pada gambar 2, sedangkan periode curah hujan kabupaten Supiori adalah 6 bulanan seperti pada gambar 3. Meskipun Supiori memiliki periode curah hujan 6 bulanan, tetapi curah hujan di Kabupaten Supiori hampir merata sepanjang tahun.

BMKG juga mencatat bahwa ratarata penyinaran matahari setiap bulan adalah 140,8 jam, di mana penyinaran terbesar terjadi pada bulan Januari yaitu 203,1 jam dan paling kecil pada bulan Juni hanya $69,1 \mathrm{jam}$. Sementara pantauan ratarata kecepatan angin setiap bulan masih tergolong normal yaitu 3,7 knots dan tekanan udara sebesar 1.007,1 mba. 

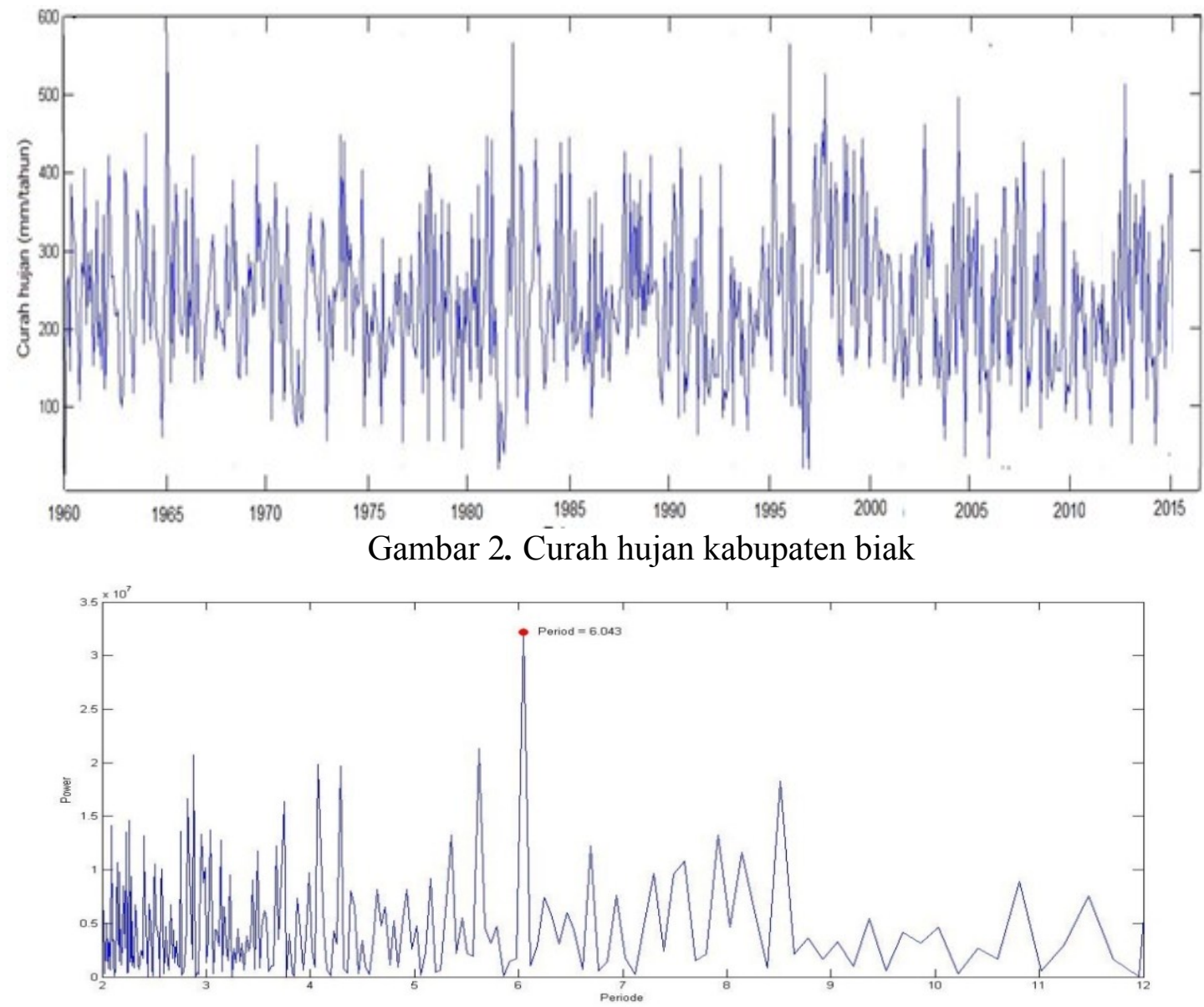

Gambar 3. Periode curah hujan Kabupaten biak

c) Suhu Dan Kelembaban

Berdasarkan hasil pencatatan

Stasiun Meteorologi Kelas I Frans Kaisiepo Biak pada tahun dilaporkan bahwa suhu udara rata- rata di wilayah Kabupaten Biak Numfor adalah 27,1 C dengan kelembaban udara rata- rata $86,3 \%$, sehingga dapat disimpulkan bahwa daerah Kabupaten Biak Numfor termasuk kategori panas. Hal ini juga dapat dilihat dari suhu udara minimum sekitar $24,5^{\circ} \mathrm{C}$ sementara suhu maksimum mencapai $30 \mathrm{C}$.

\subsection{Daerah Aliran Sungai}

Berdasarkan Peraturan Pemerintah

No 38 Tahun 2011 yang dimaksud dengan sungai adalah alur atau wadah air alami dan/atau buatan berupa jaringan pengaliran air beserta air di dalamnya, mulai dari hulu sampai muara, dengan dibatasi kanan dan kiri oleh garis sempadan. Sedangkan yang dimaksud dengan Daerah Aliran Sungai (DAS) adalah suatu wilayah daratan yang merupakan satu kesatuan dengan sungai dan anak-anak sungainya, yang berfungsi menampung, menyimpan, dan mengalirkan air yang berasal dari curah hujan ke laut secara alami, yang batas di darat merupakan pemisah topografis dan batas di laut sampai dengan daerah perairan yang masih terpengaruh aktivitas daratan.

Kabupaten Supiori memiliki beberapa aliran Sungai, antara lain sungai Wafor, Sungai Yawerna, Sungai Puweri, Sungai Kobari Jaya, Sungai Wabudori, Sungai Koiryakam, Sungai Wayori dan beberapa sungai kecil yang lain. Sungaisungai yang berada dibagian utara Pulau 
Supiori bermuara di Samudera Pasifik, sedangkan sungai yang berada dibagian selatan bermuara di Teluk Korido. Sungai Wafor dan Yawerna merupakan sungai yang mengalir di di Distrik Supiori Timur bermuara di Samudra Pasifik dan Selat Sorendiweri. Sungai Puweri dan Sungai Koberi Jaya mengalir di Distrik Supiori Utara dan bermuara di Samudera Pasifik. Adapun sungai yang mengalir di Distrik Supiori Barat adalah Sungai Wabudori, Sungai Koiryakam dan Sungai Wayori ketiga sungai ini juga bermuara di Samudera Pasifik. Untuk Distrik Supiori selatan terdapat Sungai Biniki, Sungai Maryaidori, Sungai dori dan sungai-sungai kecil lainnya yang bermuara di Teluk Korido (Gambar 4).

a) Daearah Aliran Sungai Di Distrik Supiori Timur
Distrik Supiori timur memiliki beberapa Aliran Sungai diantaranya adalah Sungai Wafor, Sungai Wakre, Sungai Yawerma, Sungai Marsram dan beberapa sungai kecil lainnya. Sungai-sungai di bagian utara bermuara di Samudera Pasifik, dan sungai-sungai di bagian timur bermuara di selat Sorendiweri. Sungai terbesar di Supiori Timur adalah Sungai Wafor. Daerah Aliran Sungai Wafor memiliki luas \pm 5.709 Ha (Gambar 5), berada di Sungai Wafor memiliki anakanak sungai yang secara geografis terletak antara 135 36'06"E sampai dengan $135^{\circ} 42^{\prime} 41^{\prime \prime E ~ B u j u r ~ T i m u r ~ d a n ~} 0^{\circ} 42^{\prime} 23^{\prime \prime S}$ sampai dengan $0^{\circ} 46^{\prime} 55^{\prime \prime S}$ Lintang Selatan. Sungai Wafor dengan beberapa anak sungainya, memiliki pola aliran dendritik dan memiliki panjang $\pm 12 \mathrm{~km}$ berhulu di Pegunungan Supiori dan bermuara di Samudera Pasifik.

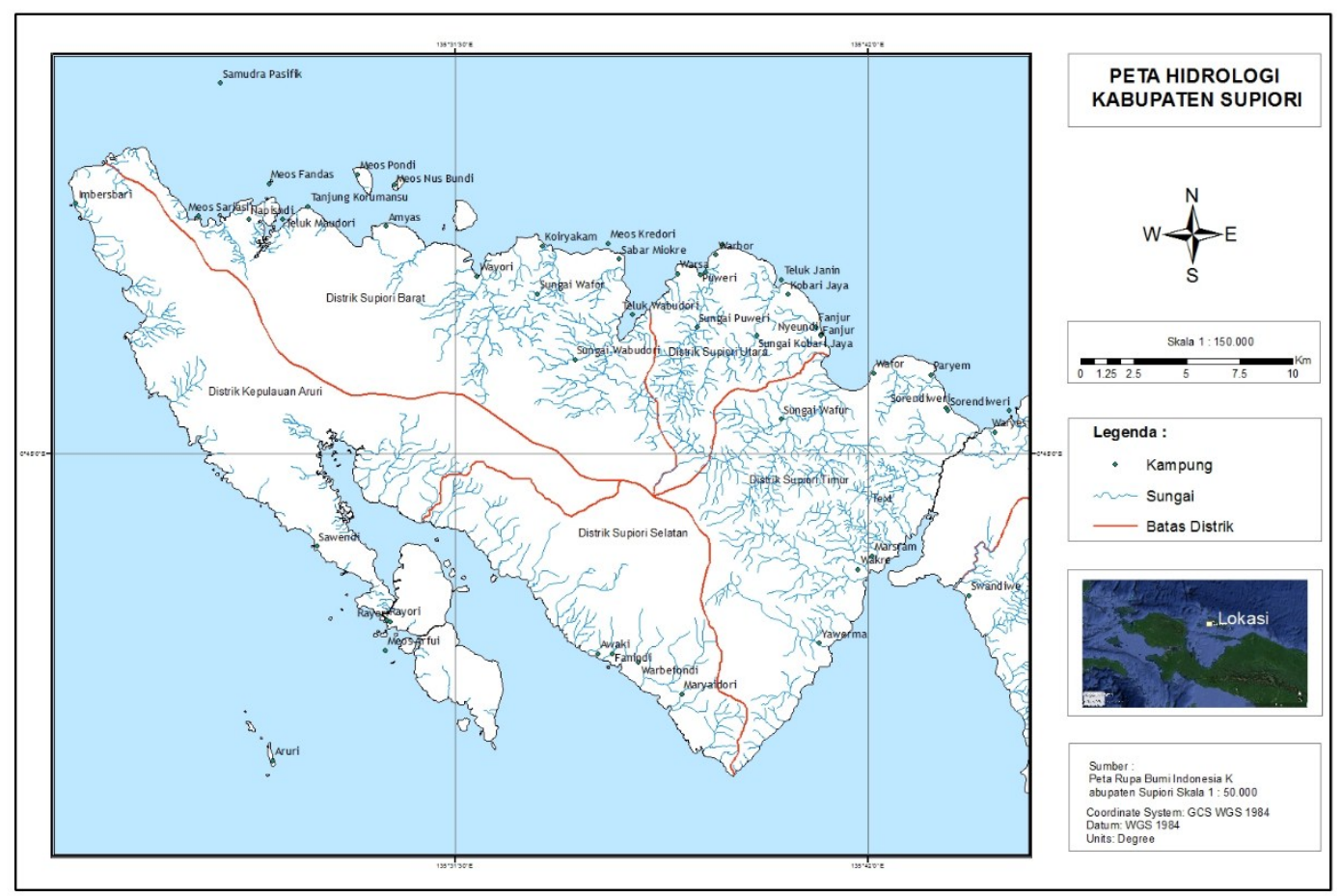

Gambar 4. Sungai-Sungai di Kabupaten Supiori. 


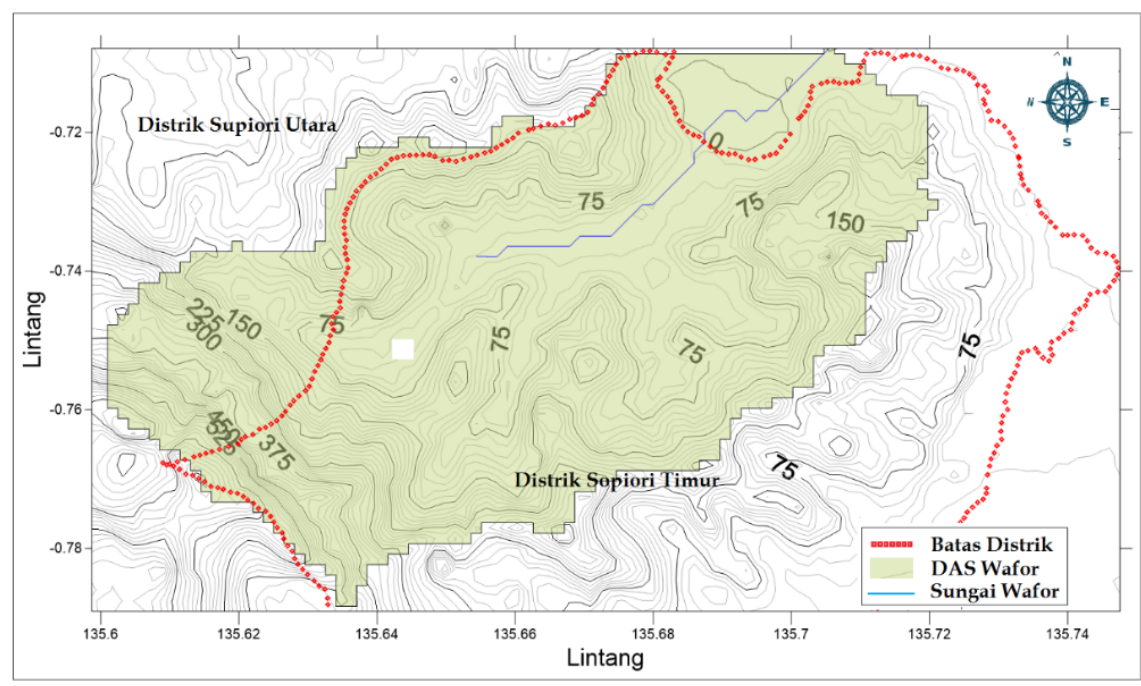

Gambar 5. Kontur DAS Wafor

b) Morfometri Sungai

Bentuk DAS mempunyai pengaruh pada pola aliran sungai dan ketajaman puncak discharge banjir. Bentuk DAS mempengaruhi waktu konsentrasi air hujan yang mengalir menuju outlet. Semakin bulat bentuk DAS berarti semakin singkat waktu konsentrasi yang diperlukan, sehingga semakin tinggi fluktuasi banjir yang terjadi. Sebaliknya semakin lonjong bentuk DAS, waktu konsentrasi yang diperlukan semakin lama sehingga fluktuasi banjir semakin rendah. Hasil pengukuran beberapa parameter morfometri dapata dilihat pada Tabel 2.
Berdasarkan analisis spasial, Sungai Wafor yang memiliki luas $57.1 \mathrm{~km}^{2}$ dan keliling $32.7 \mathrm{~km}$, sehingga DAS tersebut masuk dalam kategori DAS kecil (BPDAS, 2013). Dilihat dari nilai faktor bentuk (Form factor/ Rf), yaitu rasio luas DAS dengan kuadrat panjang cekungan, DAS Wafor memiliki nilai 0.62 atau bentuk DAS relatif membulat. Selain dari parameter form factor, bentuk DAS juga dapat dilihat dari rasio rasio elongasi (Elongation ratio/Re), dimana DAS Wafor memiliki rasio elongasi sebesar 0.71 . Menurut Soewarno (1991), bentuk daerah aliran sungai yang membulat, debit puncak datangnya lama, begitu juga penurunannya.

Tabel 2. Hasil pengukuran morfometri

\begin{tabular}{rlr}
\hline No & \multicolumn{1}{c}{ Parameter } & \\
\hline $\mathbf{1}$ & Luas $\left(\mathrm{km}^{2}\right)$ & 57,1 \\
\hline $\mathbf{2}$ & Keliling $(\mathrm{km})$ & 32,7 \\
\hline $\mathbf{3}$ & Faktor bentuk (Form factor/ Rf) & 0.62 \\
\hline $\mathbf{4}$ & Rasio elongasi (Elongation ratio/Re) & 0,71 \\
\hline $\mathbf{5}$ & Rasio relief $($ Relief ratio/ Rh) & 0,04 \\
\hline $\mathbf{6}$ & Kerapatan drainage $($ Drainage density/ Dd $)$ & 1,03 \\
\hline $\mathbf{7}$ & Frekuensi sungai $($ Stream frequency/ $F s)$ & 2,01 \\
\hline $\mathbf{8}$ & Tekstur drainage $($ Drainage texture/ Rt $)$ & 3,52 \\
\hline $\mathbf{9}$ & Faktor bentuk (Form factor/Rf) & 1,70 \\
\hline
\end{tabular}


DAS Wafor memiliki kerapatan drainase (Dd) $1,03 \mathrm{Km} / \mathrm{Km}^{2}$, artinya setiap $1 \mathrm{~km}^{2}$ area DAS terpadat panjang total sungai 1,03 Km. Kerapatan drainase ini termasuk kategori sedang, dimana alur sungai melewati batuan dengan resistensi yang lebih lunak, sehingga angkutan sedimen yang terangkut aliran akan lebih besar. Frekuensi sungai (Stream frequency/ Fs) dan Tekstur drainage (Drainage texture/ Rt) DAS Wafor masing-masing 2.01 dan 3.52.

Parameter kerapatan drainase (Dd), Frekuensi Sungai (Fs) dan Tekstur Drainase (Dt) terutama dipengaruhi oleh faktor alami seperti iklim, curah hujan, tutupan vegetasi, jenis batuan, infiltrasi kapasitas tanah, relief dan tahap evolusi bentuk lahan. Distribusi spasial dan intensitas faktor-faktor ini secara bersamasama atau secara independen mempengaruhi kepadatan drainase suatu DAS, baik dengan meningkatkan kapasitas infiltrasi tanah maupun meningkatkan limpasan permukaan. Jika suatu area DAS dapat menginfiltrasi air hujan dalam jumlah yang signifikan, maka frekuensi aliran dan tekstur drainase akan berkurang (Strahler, A.N, 1964).

c) Struktur Sungai
Bagian dari bentuk luar sungai secara rinci dapat dipelajari melalui bagianbagian dari sungai, yang sering disebut dengan istilah struktur sungai. Struktur sungai dapat dilihat dari tepian aliran sungai (alur sungai), bantaran sungai, tebing sungai dan dasar sungai. Aliran Sungai (Alur sungai) adalah bagian dari muka bumi yang selalu berisi air yang mengalir yang bersumber dari aliran limpasan, aliran sub surface run-off, mata air dan air bawah tanah (base flow). Sungai Wafor memiliki alur sungai yang semakin lebar ke arah hilir. Di daerah hilir alur Sungai Wafor memiliki lebar antara 30-40 $\mathrm{m}$ dengan kedalaman 1.5 - 2 m (Gambar $6)$.

Bantaran Sungai merupakan bagian dari struktur sungai yang sangat rawan, terletak antara badan sungai dengan tanggul sungai, mulai dari tebing sungai hingga bagian yang datar (Forman dan Gordon, 1983). Pemisah antara Badan Sungai dan bagian yang datar atau bagian yang tidak tergenangi air di Sungai Wafor terlihat jelas, hanya saja menuju ke bagian hilir batas tersebut menjadi samar akibat adanya dataran banjir di bagian hilir. Pada saat air surut akan terlihat badan sungai, tetapi ketika air laut pasang dan di daerah hulu terjadi hujan lebat

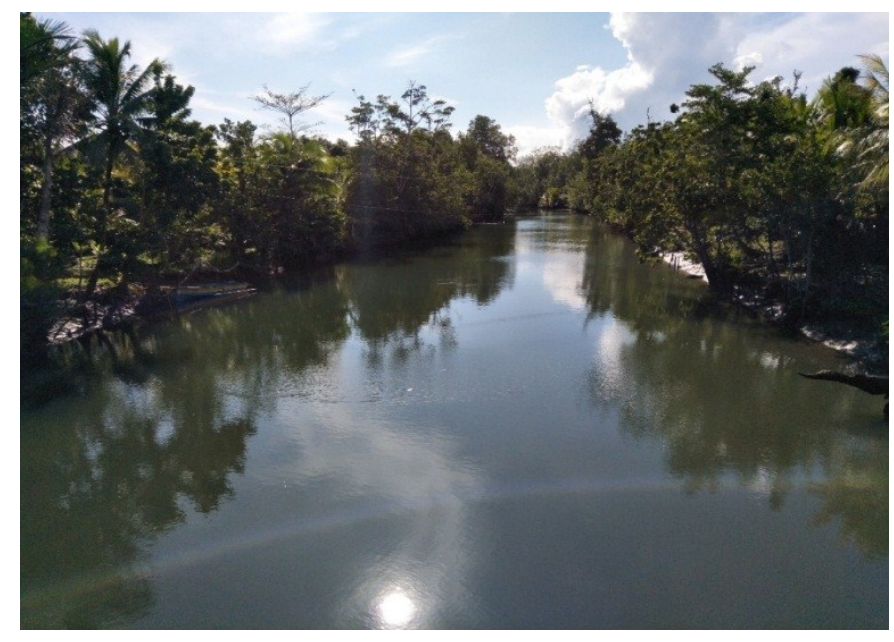

Gambar 6. Bagian hilir Sungai Wafor 
maka daerah datar yang awalnya kering akan tergenangi oleh air sungai, sehingga terlihat seperti rawa. Pada saat air pasang air laut akan mempengaruhi kada garam atau salinitas air sungai. Daerah sungai yang di pengaruhi aktivitas pasang surut dapat mencapai $\pm 1 \mathrm{~km}$ ada muara. Bantaran Sungai Wafor masih ditutup vegetasi yang cukup rapat.

Dasar Sungai Wafor sangat bervariasi, ada bagian yang relative rata (dekat muara), dan ada yang curam (daerah hulu), dengan kemiringan (Slope) maksimum mencapai lebih dari $30 \%$. Hal ini dapat dilihat dari kontur DAS Wafor dan penampang 3 Dimensi DAS Wafor pada gambar 7. Bentang alam yang menghubungkan antara dasar sungai dengan tanggul sungai disebut dengan tebing sungai. Tebing sungai umumnya membentuk lereng atau sudut lereng, yang sangat tergantung dari bentuk medannya. Semakin terjal akan semakin besar sudut lereng yang terbentuk.

d) Karakteristik sungai

Karakteristik sungai memberikan gambaran atas pola aliran sungai, profil sungai dan genetis sungai. Letak, bentuk dan arah aliran sungai, dipengaruhi antara lain oleh lereng dan ketinggian, perbedaan erosi, struktur jenis batuan, patahan dan lipatan, merupakan faktor-faktor yang menyebabkan perbedaan bentuk genetik dan pola sungai. Pola sungai adalah kumpulan dari sungai yang mempunyai bentuk yang sama, yang dapat menggambarkan keadaan profil dan genetik sungainya (Sandy, 1985). Sungai Wafor memiliki pola aliran sungai denditrik, dimana bentuknya menyerupai garis-garis pada penampang daun, dan sungai induk memperoleh aliran dari anak sungainya.

e) Lingkungan Fisik Sungai

Kedalaman sungai sangat tergantung dari jumlah air yang tertampung pada alur sungai yang diukur dari penampang dasar sungai sampai ke permukaan air. Level rataan dasar sungai pengukurannya dirata-ratakan minimal dari tiga titik yang berbeda yaitu di bagian tengah dan kanan kirinya. Kedalaman sungai Wafor antara $1.5-2 \mathrm{~m}$ (sangat tergantung kondisi pasang surut dan suplai air dari daerah tangkapan hujan). Sungai Wafor meliliki luas penampang basah $\pm 38.5 \mathrm{~m}^{2}$ (saat pengukuran pada posisi $00^{\circ}$ 44' 22.01" S dan $135^{\circ} 44^{\prime} 49.29$ " E) dan

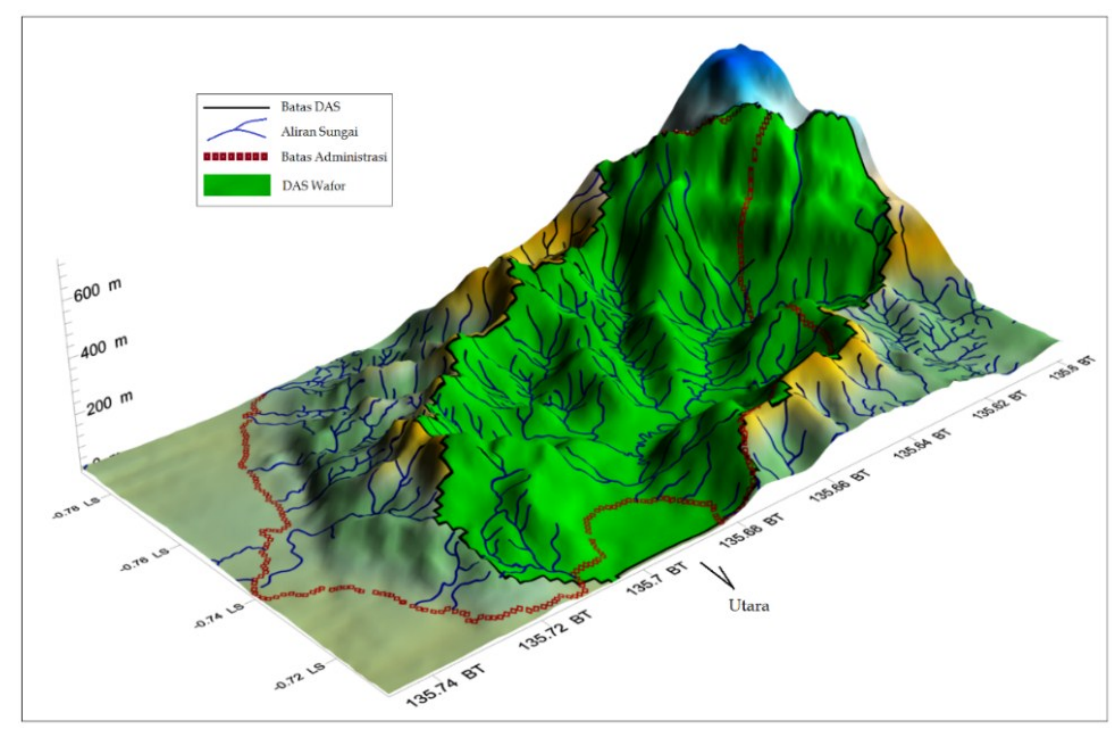

Gambar 7. Profil 3D DAS Wafor 
memiliki kecepatan rata-rata $0.1 \mathrm{~km} / \mathrm{jam}$, sehingga debit air sesaat diperkirakan mencapai $4 \mathrm{~m}^{3} / \mathrm{s}$. Berdasarkan hasil analisis lab, nilai TSS di Sungai Wafor kurang dari $5 \mathrm{mg} / \mathrm{L}$. Dengan debit sebesar $4 \mathrm{~m}^{3} / \mathrm{s}$, diperkirakan sedimen total yang terbawa aliran Sungai Wafor tidak lebih dari 0.02 $\mathrm{Kg} / \mathrm{dtk}$ atau 631 Ton/Tahun.

\subsection{Identifikasi Kawasan Bernilai Konservasi Tinggi}

a) Kawasan yang penting untuk tangkapan air (NKT 4.1)

Salah satu faktor penting yang harus diwujudkan dalam setiap sistem pengelolaan DAS adalah menjaga fungsi DAS sebagai pengatur tata air yang baik. Oleh sebab itu fungsi hidrologis DAS harus dapat terjaga secara lestari yang dicirikan oleh ketersediaan sumberdaya air yang meliputi kuantitas dan distribusi yang baik sepanjang tahun di seluruh DAS.

Curah hujan di Daerah Aliran Sungai di lokasi kajian dalam 5 tahun tarakhir tergolong tinggi rata-rata mencapai rata-rata $2764.4 \mathrm{~mm}$ per tahun dengan rerata hari hujan 22 hari. Berdasarkan analisis hidrometeorologis 22.6\% curah hujan yang jatuh di Kabupaten Supiori berada pada daerah aliran Sungai Wafor, Sungai Puweri, Sungai Wabudori, Sungai Wayori dan Sungai Biniki. Sebagian besar tangkapan air DAS tersebut berada di kawasan hutan dan cagar alam. DAS Wafor merupakan DAS terbesar diantara kelima DAS tersebut. Jumlah ketersediaan air yang mantap DAS Wafor diperkirakan mencapai $15.59 \mathrm{Juta}^{3} /$ Tahun.

Dengan kemiringan yang mencapai $30-40 \%$ dibagian hulu sungai Wafor, maka daerah ini perlu dijaga dengan baik. Keseimbangan antara curah hujan, evapotranspirasi dan aliran permukaan perlu terjaga sehingga daerah aliran sungai dapat menyimpan air pada saat curah hujan tinggi dan mengalirkan air saat curah hujan berkurang.

b) Kawasan yang penting untuk kendali erosi (NKT 4.2)

Sedimentasi yaitu proses pengendapan dari suatu material yang berasal dari angin, erosi air, gelombang laut serta gletser. Material yang dihasilkan dari erosi yang dibawa oleh aliran air dapat diendapkan di tempat yang ketinggiannya lebih rendah. Berdasarkan hasil analisis lab, nilai TSS di Sungai termasuk kategori rendah atau $<50 \mathrm{mg} / \mathrm{L}$. Total sedimen yang terbawa oleh aliran Sungai Wafor mencapai $0.002 \mathrm{Kg} / \mathrm{s}$ atau $631 \mathrm{Ton} /$ Tahun.

Dilihat dari kemiringan lereng pada bagian hulu yang mencapai $<30 \%$ dan alur sungai yang rata-rata tidak lebih dari 20 $\mathrm{Km}$, maka dapat disimpulkan bahwa Daerah Aliran Sungai bekerja efektif dalam mengendalikan erosi.

c) Kawasan yang memberikan penghalang penting bagi kebakaran yang bersifat merusak (NKT 4.3)

Jaringan sungai dan penggunaan lahan merupakan salah faktor-faktor yang menentukan resiko kebakaran hutan dan lahan selain faktor aktivitas manusia. Sebagaian besar daerah aliran sungai di Kabupaten Supiori memiliki kerapatan sedang, hal ini tentunya akan sangat membantu dalam menghalangi penyebaran titik-titik api jika terjadi kebakaran hutan.

\section{KESIMPULAN}

Kesimpulan yang dapat diperoleh dari penelitian ini antara lain :

1. Sungai Wafor memiliki rasio relief rata-rata antara 0.04, namum dibeberapa tempat terutama bagian hulu, kemiringan lereng mencapai $30 \%-40 \%$. Faktor bentuk (Form factor/ Rf) DAS Wafor memiliki nilai 0.62 atau bentuk DAS relatif membulat dan rasio 
elongasi sebesar 0.71. Daerah aliran sungai yang membulat, debit puncak datangnya lama, begitu juga penurunannya, sehingga dapat efektif dalam mengendalikan banjir.

2. DAS Wafor memiliki kerapatan drainase (Dd) $1,03 \quad \mathrm{Km} / \mathrm{Km} 2$, artinya setiap $1 \mathrm{~km} 2$ area DAS terpadat panjang total sungai 1,03 Km. Kerapatan drainase ini termasuk kategori sedang. Hal ini tentunya akan sangat membantu dalam menghalangi penyebaran titik-titik api jika terjadi kebakaran hutan. Sedimentasi di Sungai Wafor termasuk kategori rendah atau $<50$ $\mathrm{mg} / \mathrm{L}$. Dengan alur sungai rata-rata tidak lebih dari $20 \mathrm{Km}$, maka dapat disimpulkan bahwa DAS tersebut bekerja efektif dalam mengendalikan erosi.

3. Jumlah ketersediaan air yang mantap DAS Wafor diperkirakan mencapai 15.59 Juta $\mathrm{m}^{3}$ /Tahun

\section{DAFTAR PUSTAKA}

Arsyad, S, 2010. Konservasi Tanah dan Air, Institut Pertanian Bogor, Bogor.

Asdak, C, 2010. Hidrologi dan Pengelolaan Daerah Aliran Sungai. Gadjah Mada University Press, Yogyakarta.

Georg Petersen. 2005. Hydrological Impacts Assessment Study. United States Agency for International Development.
Bayong Tjasyono H. K., 2004. Klimatologi, Penerbit ITB, Bandung.

Soewarno, 1991. Hidrologi Pengukuran dan Pengolahan Data Aliran Sungai (Hidrometri), Nova, Bandung.

HCV Toolkit Indonesia Konsorsium Revisi HCV Toolkit Indonesia. 2008. Panduan Kawasan Bernilai Konservasi Tinggi.

Forman, Richard and Michel Gordon. 1983. Lansdcape Ecology. John Wiley \& Son; New York.

Sandy, IM, 1985. DAS-Ekosistem Penggunaan Tanah. Publikasi Direktorat Taguna Tanah Departemen Dalam Negeri (Publikasi 437).

Badan Pusat Statistik (BPS). 2019. Kabupaten Supiori Dalam Angka 2019.

Peraturan Direktur Jenderal Bina Pengelolaan Daerah Aliran Sungai Dan Perhutanan Sosial Nomor : P. 3/V-SET/2013 Tentang Pedoman Identifikasi Karakteristik Daerah Aliran Sungai

Soewarno, 1991, Hidrologi Pengukuran dan Pengolahan Data Aliran Sungai (Hidrometri), Nova, Bandung.

Strahler, A. 1964. Quantitative Geomorphology of Drainage Basins and Channel Networks. In: Chow, V., Ed., Handbook of Applied Hydrology, McGraw Hill, New York. 